Int. J. Electrochem. Sci., 13 (2018) 3023 - 3049

International Journal of

ELECTROCHEMICAL

SCIENCE

www.electrochemsci.org

\title{
Effect of Green Corrosion Inhibition by Prunus persica on AISI 1018 Carbon Steel in $0.5 \mathrm{M} \mathrm{H}_{2} \mathrm{SO}_{4}$
}

\author{
A. Rodríguez-Torres ${ }^{1}$, O. Olivares-Xometl ${ }^{2}$, M. G. Valladares-Cisneros ${ }^{3, *}$, \\ J. G. González-Rodríguez, \\ ${ }^{1}$ Centro de Investigaciones en Ingeniería y Ciencias Aplicadas, Universidad Autónoma del Estado de \\ Morelos, Ave. Universidad 1001, Chamilpa, C.P. 62209, Cuernavaca, Morelos, México. \\ ${ }^{2}$ Facultad de Ingeniería Química, Benemérita Universidad Autónoma de Puebla, Av. San Claudio, \\ Ciudad Universitaria. Col. San Manuel, Puebla 72570, Puebla, México \\ ${ }^{3}$ Facultad de Ciencias Químicas e Ingeniería, Universidad Autónoma del Estado de Morelos, Ave. \\ Universidad 1001, Chamilpa, C.P. 62209, Cuernavaca, Morelos, México. \\ *E-mail: mg.valladares@uaem.mx
}

doi: $10.20964 / 2018.03 .40$

Received: 26 June 2017 / Accepted: 9 January 2018 / Published: 5 February 2018

The extract of Prunus persica (P. persica) leaves was studied as a green corrosion inhibitor (GCI) of AISI 1018 steel in $0.5 \mathrm{M} \mathrm{H}_{2} \mathrm{SO}_{4}$ at $25^{\circ} \mathrm{C}$. The corrosion inhibition efficiency (CIE) was established by the weight loss, potentiodynamic polarization curves (PPC) and electrochemistry impedance spectroscopy (EIS) techniques. The results showed that the IE was directly proportional to the inhibitor concentration, obtaining a maximum IE at $600 \mathrm{ppm}(97 \%)$ with a residence time of $6 \mathrm{~h}$. The analysis of the electrochemical parameters from the polarizations curves confirmed that the P. persica extract behaved as a mixed-type GCI with cathodic predominance. The micrographs confirmed negligible damage on the steel surface when protected with the $P$. persica as GCI against the corrosive medium. The GC-MS analysis detected a high concentration of $\alpha$-Tocopherol (vitamin E) and $\beta$-Sitosterol among the phytochemicals present in the P. persica extract. Lactuca sativa (L. sativa) and Artemia salina Leanch (A. salina) were used as bioindicators of possible toxic effects exerted by the GCI, finding that the germination of seeds and radicle development of L. sativa were little affected (30\% of inhibition for hypocotile develop) by the $P$. persica extract at $600 \mathrm{ppm}$. However, the GCI turned to be harmless for the second bioindicator (A. salina).

Keywords: Prunus persica, Green corrosion inhibitor, AISI 1018 Carbon steel, Artemia salina and Lactuca sativa.

$\underline{\text { FULL TEXT }}$ 
(C) 2018 The Authors. Published by ESG (www.electrochemsci.org). This article is an open access article distributed under the terms and conditions of the Creative Commons Attribution license (http://creativecommons.org/licenses/by/4.0/). 